\title{
POLÍTICAS PARA CONSERVAÇÃO DE ÁREAS VERDES URBANAS PARTICULARES EM CURITIBA - O CASO DA BACIA HIDROGRÁFICA DO RIO BELÉM
}

\author{
Mauri César Barbosa Pereira*, Anadalvo Juzeiro dos Santos**, Ricardo Berger***, \\ Anselmo Chaves Neto**** \\ *Eng. Florestal, M.Sc. - mauri@terra.com.br \\ **Eng. Florestal, Dr., Depto. de Economia Rural e Extensão, UFPR - ajsantos@floresta.ufpr.br \\ ***Eng. Florestal, Ph.D., Depto. de Economia Rural e Extensão, UFPR - berger@bsi.com.br \\ ****Matemático, Eng. Civil, Ph.D., Depto. de Estatística, UFPR - anselmo@est.ufpr.br \\ Recebido para publicação: 18/06/2004 - Aceito para publicação: 10/06/2005
}

\begin{abstract}
Resumo
O trabalho aborda a influência do Imposto Predial Territorial Urbano (IPTU) na conservação das áreas verdes urbanas particulares na bacia hidrográfica do Rio Belém, localizada no Município de Curitiba, capital do estado do Paraná. A análise foi realizada nas áreas verdes da bacia hidrográfica do Rio Belém que representam $20 \%$ da área do município de Curitiba e abrigam aproximadamente $50 \%$ da população curitibana. Na bacia hidrográfica do Rio Belém, conforme os dados trabalhados, existem 937 bosques nativos relevantes, o que representa $8,6 \%$ da área da bacia, dos quais $93,93 \%$ são bosques localizados em imóveis particulares. A pesquisa foi realizada em 126 amostras localizados na bacia hidrográfica. As análises evidenciaram que o motivo da permanência desses fragmentos de florestas no meio urbano está relacionado ao período de anos que os proprietários residem nos imóveis, que ultrapassa 20 anos, e os laços culturais, históricos e ecológicos que eles têm com os antecedentes que mantiveram essas florestas. $O$ trabalho evidenciou que a maioria dos proprietários não usufrui do benefício da redução do IPTU para a conservação dos bosques, e para os que usufruem desses benefícios, a redução alcança, na maioria dos casos, $30 \%$ do IPTU.

Palavras-chave: Florestas urbanas particulares; bacias hidrográficas e áreas verdes; conservação florestal; Curitiba - Brasil.
\end{abstract}

\begin{abstract}
Policies for private conservation of green urban areas in Curitiba - the case of Belém River watershed. The study analyses the influence of the municipal taxation system - IPTU - for the conservation of private green areas within the watershed of river Belém, in Curitiba, capital of the State of Parana. Within the watershed of River Belem are found a total of 937 plots of relevant native woodlots representing $8,6 \%$ of the total watershed area. Out of these, $93,93 \%$ woodlots belong to individual owners. For the purpose of the study a questionnaire was produced and a total of 126 real estate owners were consulted within the watershed. The results of the study showed that the presence of the referred forest fragments within the urban context is related to the length of residence $(+20$ years) together with the culture, the history and the ecological ties kept by present owners with their ancestors who had since long protected these forests. In direct relation to taxation, it was observed that more than half of the owners consulted do not enjoy IPTU tax reduction (due to conservation) granted by law. And those enjoying the tax reduction have a benefit of $30 \%$ in the value of the tax levied.

Keywords: Private urban forests; watershed and green areas; forest conservation; Curitiba - Brazil.
\end{abstract}

\section{INTRODUÇÃO}

A conservação de remanescentes florestais nas áreas urbanas encontra sérias barreiras devido às pressões do processo de urbanização, com a tendência de ocupar todos os espaços possíveis. As legislações ambientais aplicadas para o meio rural, a exemplo do Código Florestal, encontram sérias 
dificuldades de aplicabilidade no meio urbano, especialmente em relação aos critérios para a conservação das matas ciliares.

Os remanescentes florestais em áreas urbanas contam com poucos instrumentos que efetivamente conseguem resguardá-los, exceto as áreas que são transformadas em parques e bosques municipais de domínio público, para fins de lazer ou mesmo de conservação de espécies. Outras iniciativas são realizadas através da criação de Áreas de Proteção Ambiental (APA) no âmbito municipal, implantadas no sentido de disciplinar o uso do solo e conservar espaços verdes nas áreas urbanas e periurbanas. Poucas são as iniciativas para a conservação de florestas em imóveis particulares urbanos. A conservação de remanescentes florestais particulares em áreas urbanas, também denominados espaços verdes, espaços livres ou bosques nativos e relevantes (Curitiba, 2004), contam com poucos instrumentos legais efetivamente aplicáveis, exceto alguns mecanismos incluídos nas Leis de Zoneamento do Uso do Solo em algumas cidades brasileiras.

As florestas, em geral, possuem um conjunto de benefícios diretos e indiretos, que se relacionam com os aspectos sociais, econômicos e ambientais, os quais são amplamente difundidos e conceituados.

Grey e Deneke (1978) denominam e classificam as florestas urbanas em públicas e privadas.

No mesmo sentido, Milano, citado por Hardt (1994), afirma que as áreas verdes urbanas classificam-se como áreas livres nas cidades, com características predominantemente naturais independentemente do porte da vegetação. A autora estabelece o conceito pelo qual as áreas verdes urbanas compreendem um conjunto devidamente organizado de áreas urbanas selecionadas, podendo ser enquadradas em pelo menos 2 (duas) categorias, as públicas e as privadas.

Guzzo (2002) comenta sobre a dificuldade em relação aos termos utilizados para definir as áreas verdes urbanas, especialmente em relação às diferenciações entre termos como áreas livres, espaços abertos, áreas verdes, sistemas de lazer, praças, parques urbanos, unidades de conservação em área urbana, arborização urbana. $\mathrm{O}$ autor comenta em seu trabalho sobre os benefícios e valores das áreas verdes, que são expressos pelas funções ecológicas, sociais, estéticas, educativas e psicológicas.

Em relação à importância das florestas em áreas urbanas, os planejadores urbanos mencionam os seus amplos benefícios. Griffth e Silva, citados por Hildebrand (2001), comentam que as experiências brasileiras na conservação de áreas verdes urbanas ainda são incipientes. Esses autores consideram que as áreas verdes desempenham um papel significativo e fundamental para o planejamento urbano, em função dos aspectos de localização em relação às áreas mais densamente urbanizadas, de facilitação da vida das pessoas nas proximidades onde vivem, de interação com o plano diretor da cidade, de distribuição das áreas nos diversos espaços e de limitação de recursos financeiros para o sistema de áreas verdes. Nilsson e Randrup (1997) comentam que as árvores interceptam particulas de matéria e absorvem poluentes gasosos como o ozônio, o dióxido de enxofre e o dióxido de nitrogênio, eliminando-os da atmosfera.

A distribuição e índices de cobertura de áreas verdes urbanas é outro aspecto importante. Nunes (1992) destaca a importância de que a vegetação seja distribuída homogeneamente na cidade, visando maior eficiência ecológica e socioeconômica. O autor comenta que, dependendo da política ambiental da cidade, o índice de áreas recebe distintas contribuições, tanto com áreas públicas quanto privadas.

Em termos de índice adequado de área verde por habitante, Poland (1973), citado por Milano e Disperati (1987), comenta que a Associação Nacional de Recreação dos Estados Unidos recomendou, em trabalho publicado em 1956, que o referido índice deveria variar entre 28 e $40 \mathrm{~m}^{2}$ por habitante. Em relação a esses índices, os autores citam que na Alemanha Ocidental, segundo Cavalheiro (1982), este índice é de $13 \mathrm{~m}^{2}$ por habitante, dos quais $6 \mathrm{~m}^{2}$ de parques de bairro/hab e $7 \mathrm{~m}^{2}$ de parques distritais/hab. Entretanto, avalia que, de forma geral, o índice adequado deva ser de aproximadamente $33,4 \mathrm{~m}^{2} / \mathrm{hab}$ no urbano.

Em relação às áreas verdes em Curitiba, Miguez (2001) comenta que em 1974 foi realizado o primeiro levantamento de áreas verdes de Curitiba, ocasião em que foram mapeadas 93 áreas com cobertura vegetal significativas, totalizando 392,7 ha caracterizados como Bosques de Preservação Permanente. Em 1982, foram mapeadas e cadastradas 208 novas áreas significativas, totalizando 2.017,7 ha. Posteriormente, em trabalho realizado por Milano e Disperatti para a FUPEF, em 1987, para o mapeamento das áreas verdes do município de Curitiba, mediante convênio firmado com a Secretaria Municipal de Meio Ambiente de Curitiba (SMMA), foram identificados $65.190 .468 \mathrm{~m}^{2}$ de vegetação, o que representava $15,05 \%$ da área do município. Estabeleceu-se que Curitiba tinha o índice de 50,15 $\mathrm{m}^{2} /$ hab, em 1987, o que possibilitou a criação de índices por região administrativa, as denominadas 9 
"administrações regionais": Matriz, Boqueirão, Cajuru, Boa Vista, Santa Felicidade, Campo Comprido, Portão, Pinheirinho e Umbará. Esses dados estratificados por regiões administrativas da prefeitura passaram a demonstrar as diferentes concentrações de áreas verdes, desde $3,44 \mathrm{~m}^{2} / \mathrm{hab}$ na região mais central até $2.624,76 \mathrm{~m}^{2} /$ hab em regiões menos urbanizadas, como a região do Umbará.

A quantificação mais recente das áreas verdes de Curitiba foi realizada em 2000, por Miguez (2001), utilizando métodos mais precisos, com ortofotocartas e os maciços vegetais com áreas acima de $100 \mathrm{~m}^{2}$, quantificados por bairros e microbairros. O mapeamento adotou a mesma tipologia apresentada pela FUPEF em 1987. Esse mapeamento resultou na identificação de $77.786 .020,60 \mathrm{~m}^{2}$ de áreas verdes, ou $17,97 \%$ da área física do município, o que constitui um índice de $49,02 \mathrm{~m}^{2} / \mathrm{hab}$ de área verde, considerando os dados do IBGE de 2000. Uma parcela dos remanescentes florestais de Curitiba está inserida nos parques municipais e APAs de Curitiba, que podem ser denominadas de florestas públicas, totalizando 3.377.898,48 $\mathrm{m}^{2}$, que representam 4,34\% do total de áreas verdes mapeadas em 2000.

As iniciativas e mecanismos para proteção das florestas particulares em áreas urbanas são quase inexistentes. Os poucos mecanismos existentes se referem a florestas nas áreas rurais. Segundo Santos (1996), na área florestal os instrumentos fiscais têm por objetivo a conservação, valorização ou extensão da área florestal, ou ainda penalizar pela má utilização desses recursos. Ao mesmo tempo, o autor afirma que a política fiscal também dispõe de certo número de isenções tributárias com a finalidade de incentivar a atividade florestal.

No Brasil, os mecanismos tributários conhecidos para a conservação de florestas na atualidade são o Imposto sobre a Circulação de Mercadorias e Serviços (ICMS) Ecológico e o Imposto Territorial Rural (ITR), aplicados para as Reservas de Particulares do Patrimônio Natural (RPPN).

Segundo Loureiro (2002), o ICMS é o tributo mais importante no âmbito estadual, representando $90 \%$ da receita dos tributos dos estados. Em relação ao ICMS Ecológico, o autor comenta ser a forma criada para buscar alternativas para o financiamento público das administrações municipais, em situações onde existem significativas restrições de uso do solo para o desenvolvimento de atividades econômicas.

O ITR, segundo Torres citado por Pires (1999), é um tributo com a finalidade marcadamente extrafiscal, possuindo o objetivo principal de promover a reforma agrária e a redistribuição de terras no país. Na pratica, as isenções tributárias mais importantes do ITR foram estabelecidas pela Instrução Normativa (IN) $n^{0} 60$, de 06 de junho de 2001, da Secretaria da Receita Federal (SRF), compreendendo as áreas florestais de interesse ambiental de preservação permanente, sem destinação comercial e que estejam descritas no artigo $2^{0}$ do Código Florestal, Lei $\mathrm{n}^{0} 4.771$, de 15 de setembro de 1965, e a isenção sobre áreas de interesse ambiental de utilização limitada, que compreende as áreas de reserva legal descritas no artigo 16 do Código Florestal.

Nas áreas urbanas, no âmbito da política fiscal, o Imposto Predial e Territorial Urbano (IPTU) figura como um dos principais tributos, que é classificado como imposto sobre o patrimônio. Segundo Dias (2004), o imposto sobre a propriedade territorial urbana, em sua origem, dividia-se em dois tributos distintos: o imposto predial e o territorial. A unificação só veio com a Carta Constitucional de 1946, que passou a denominá-lo de imposto predial e territorial urbano, de competência dos municípios. O IPTU foi regulamentado pelo Código Tributário Nacional, Lei no 5.172, de 25 de outubro de 1966, na seç̧ão II, que rege o Imposto sobre Propriedade Predial e Territorial Urbana.

No que diz respeito aos mecanismos em áreas urbanas, a principal experiência efetivamente implantada e ainda pouco conhecida é a da Prefeitura Municipal de Curitiba, que a partir de 1972 - Lei 4.199, de 8 de maio, sobre o zoneamento do uso do solo -, criou o Setor Especial de Áreas Verdes. Esse sistema sofreu um processo crescente de regulamentação e aperfeiçoamento, restringindo o uso de solo em áreas com remanescentes florestais nativos significativos, pertencentes a particulares. A iniciativa de Curitiba teve por finalidade incentivar a conservação dos remanescentes de florestas no perímetro urbano, denominados bosques nativos e nativos relevantes, orientando a intervenção do setor privado nessas áreas e proporcionando que eles recebam incentivos para sua conservação, mediante a isenção ou redução do Imposto Predial Territorial Urbano (IPTU). Esses incentivos e benefícios fiscais para os proprietários das áreas foram efetivados a partir de 1986 pela Lei 6.819, com a regulamentação do Setor Especial de Áreas Verdes, mediante a redução do IPTU, como mecanismo para a manutenção dos remanescentes florestais em terrenos privados. Em 12 de dezembro de 1993, a Lei $\mathrm{n}^{\circ} 8.353$ dispôs sobre o monitoramento da vegetação de porte arbóreo e estímulos à conservação das áreas verdes no Município de Curitiba e alterou os critérios da Lei $n^{\circ}$ 9.819. Entretanto, no ano de 2000, com a instituição do Código Florestal Municipal 
através da Lei 9.806, de 03 de janeiro, incorporaram-se ao Setor Especial de Áreas Verdes os denominados bosques nativos relevantes, passando então as vegetações urbanas remanescentes e representativas a denominarem-se bosques nativos relevantes (Curitiba, 2004).

Em relação ao incentivo à conservação das áreas verdes, a legislação específica que os proprietários de terrenos integrantes do Setor Especial de Áreas Verdes gozarão de isenção ou redução sobre o valor do terreno, para o cálculo base do Imposto Predial e Territorial Urbano (IPTU), proporcionalmente à taxa de cobertura florestal, de acordo com critérios estabelecidos em lei. A Lei 9.806/2000 permite que a redução de IPTU seja aplicada nos terrenos cadastrados com cobertura florestal de $10 \%$ a $80 \%$, o que resulta em percentuais de redução do imposto nas faixas de 30 a $100 \%$.

Foi com a finalidade de identificar a aplicabilidade e respostas do sistema de benefícios da conservação das áreas verdes urbanas que esta pesquisa foi desenvolvida. A pesquisa teve por objetivo avaliar, sob a ótica dos proprietários, os benefícios da aplicação dos instrumentos da política municipal de meio ambiente de Curitiba para a conservação dos bosques nativos relevantes na região da Bacia Hidrográfica do Rio Belém, cadastrados no Sistema Especial de Áreas Verdes. Complementarmente, os objetivos específicos da pesquisa compreenderam: i) realizar uma caracterização geral das áreas verdes na bacia hidrográfica do Rio Belém; ii) identificar a motivação dos proprietários para a conservação dos bosques nativos e relevantes nos imóveis; iii) identificar o conhecimento que os proprietários possuem sobre os critérios legais ambientais de uso dos imóveis com bosques; iv) identificar e qualificar a aplicação dos critérios legais que proporcionam os benefícios da redução do IPTU para os imóveis com bosques nativos e relevantes; v) identificar e avaliar a percepção sobre benefícios da existência dos bosques nativos e relevantes nos imóveis; vi) verificar a incidência de infrações ambientais sobre a utilização dos bosques nos imóveis.

\section{MATERIAL E MÉTODO}

Capital do Estado do Paraná, Curitiba está localizada na região Sul do Brasil, com altitude média de 934,6 m do nível do mar. A área total do município é de 43.217 hectares. De acordo com o Instituto de Pesquisa e Planejamento Urbano de Curitiba (IPPUC, 2004), a população de Curitiba em 2000 era de 1.587.315 habitantes. Segundo dados da Secretaria Municipal de Meio Ambiente de Curitiba (SMMA), a bacia hidrográfica do Rio Belém possui área física de $87.846 .086,27 \mathrm{~m}^{2}$, ou 8.784,60 hectares, o que representa $20,03 \%$ da área física do município.

Os bosques nativos relevantes na bacia hidrográfica do Rio Belém, com base no mapeamento realizado em 2000, totalizam 937 áreas, com um total de 7.609.208,74 $\mathrm{m}^{2}$, o que corresponde a um índice de $8,6 \%$ de áreas verdes na referida bacia. Nas figuras 1 e 2, pode ser visualizada a distribuição dos bosques nativos relevantes no município de Curitiba e na bacia hidrográfica do Rio Belém, respectivamente.

Do total de bosques nativos relevantes $\left(77.786 .020,60 \mathrm{~m}^{2}\right)$ de Curitiba, 9,7\% $\left(7.609 .208,74 \mathrm{~m}^{2}\right)$ estão localizados na área física da bacia hidrográfica do Rio Belém. O total de bosques nativos relevantes públicos na bacia hidrográfica do Rio Belém é de 11, perfazendo uma área de $450.157,68 \mathrm{~m}^{2}$, que estão inseridos nas unidades de conservação do município, representando 5,92\% do total dos bosques existentes na bacia.

Excluindo as áreas dos bosques públicos do total de áreas de bosques nativos relevantes mapeados na bacia do Rio Belém, os bosques nativos relevantes particulares na bacia perfazem 7.159.051,10 $\mathrm{m}^{2}$, o representa 94,08\% deste total. O índice de áreas verdes na bacia, de acordo com os dados de 2000, é de 8,6\% em relação à área da bacia, sendo que o índice de bosques particulares é de $8,14 \%$, e o de bosques públicos, $0,46 \%$ em relação à área dessa bacia hidrográfica.

Para o dimensionamento adequado da amostra, adotou-se a metodologia de estimação da proporção populacional. No caso, essa proporção retratou o número de bosques cujos proprietários recebem algum tipo de redução ou isenção de IPTU devido à existência de bosques relevantes em suas propriedades, resultando em uma amostra de 126 bosques. O sorteio das amostras foi realizado ao acaso, em toda a região da bacia do rio Belém, sendo os bosques numerados de 1 a 126. Foram considerados os 937 bosques, dos quais 154 já estavam cadastrados e 783 em fase de cadastramento. De acordo com informações da SMMA, ambas as situações possuem os mesmos critérios legais previstos para estímulo de redução e isenção do IPTU. 


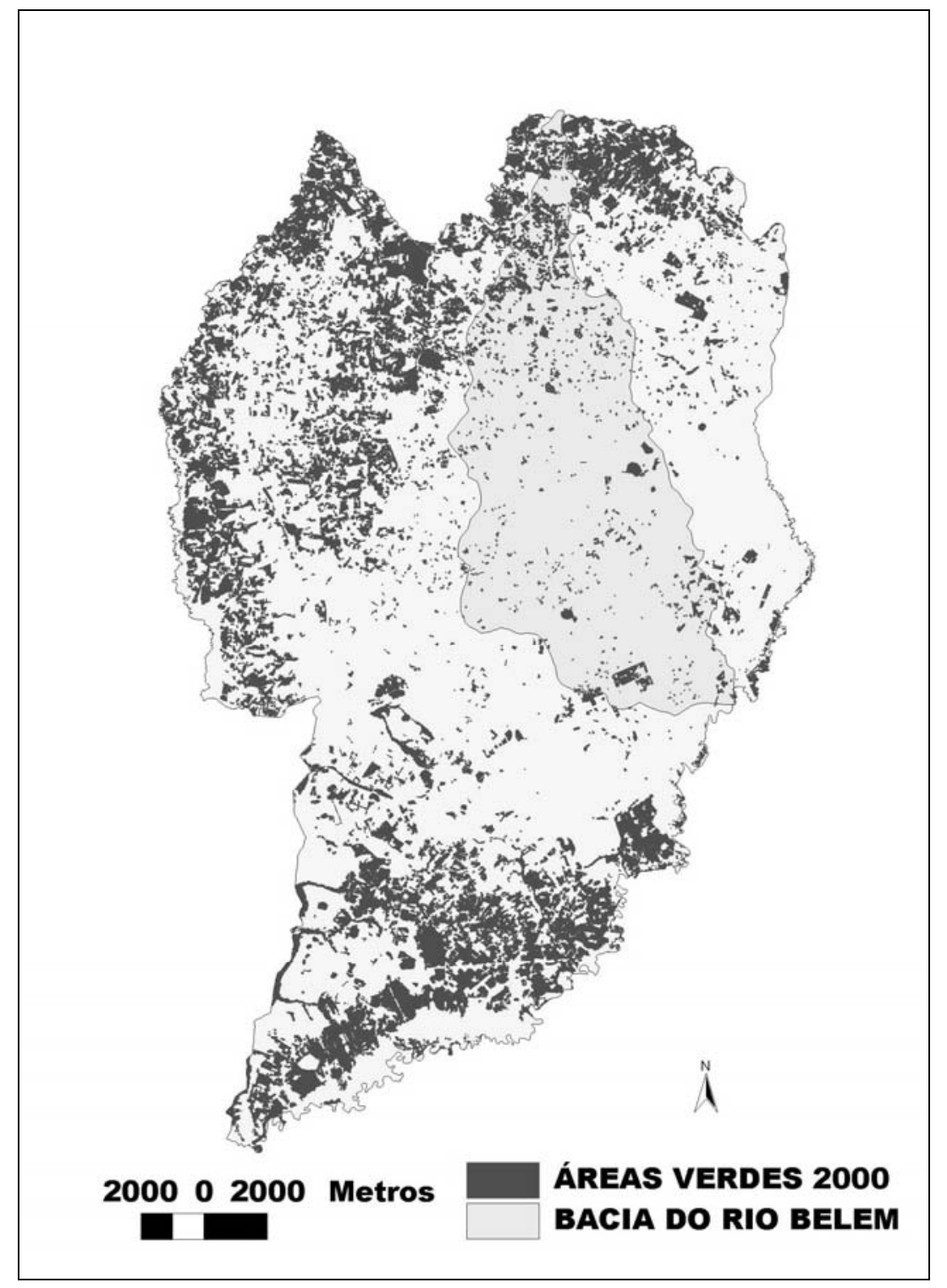

Figura 1. Distribuição das áreas verdes no município de Curitiba e na região das bacias hidrográficas. Figure 1. Distribution of the green areas in the municipal district of Curitiba and in watershed area.

Para a pesquisa, foi elaborado um questionário que foi aplicado com base no sorteio realizado para os 937 bosques cadastrados na área da bacia hidrográfica do rio Belém. As entrevistas foram realizadas com os proprietários nas 126 amostras selecionadas. O questionário foi estruturado em 2 (duas) partes, sendo a segunda subdividida em 4 (quatro) temas, compreendendo os seguintes itens:

a) Primeira parte: identificação do proprietário e características do imóvel (edificado e não edificado).

b) Segunda parte: itens aplicáveis sobre os benefícios da política municipal de meio ambiente:

- motivação para conservação dos bosques;

- critérios ambientais legais para uso do imóvel e do bosque;

- redução do IPTU sobre o imóvel;

- benefícios e usos do imóvel com bosque;

- infrações ambientais cometidas. 


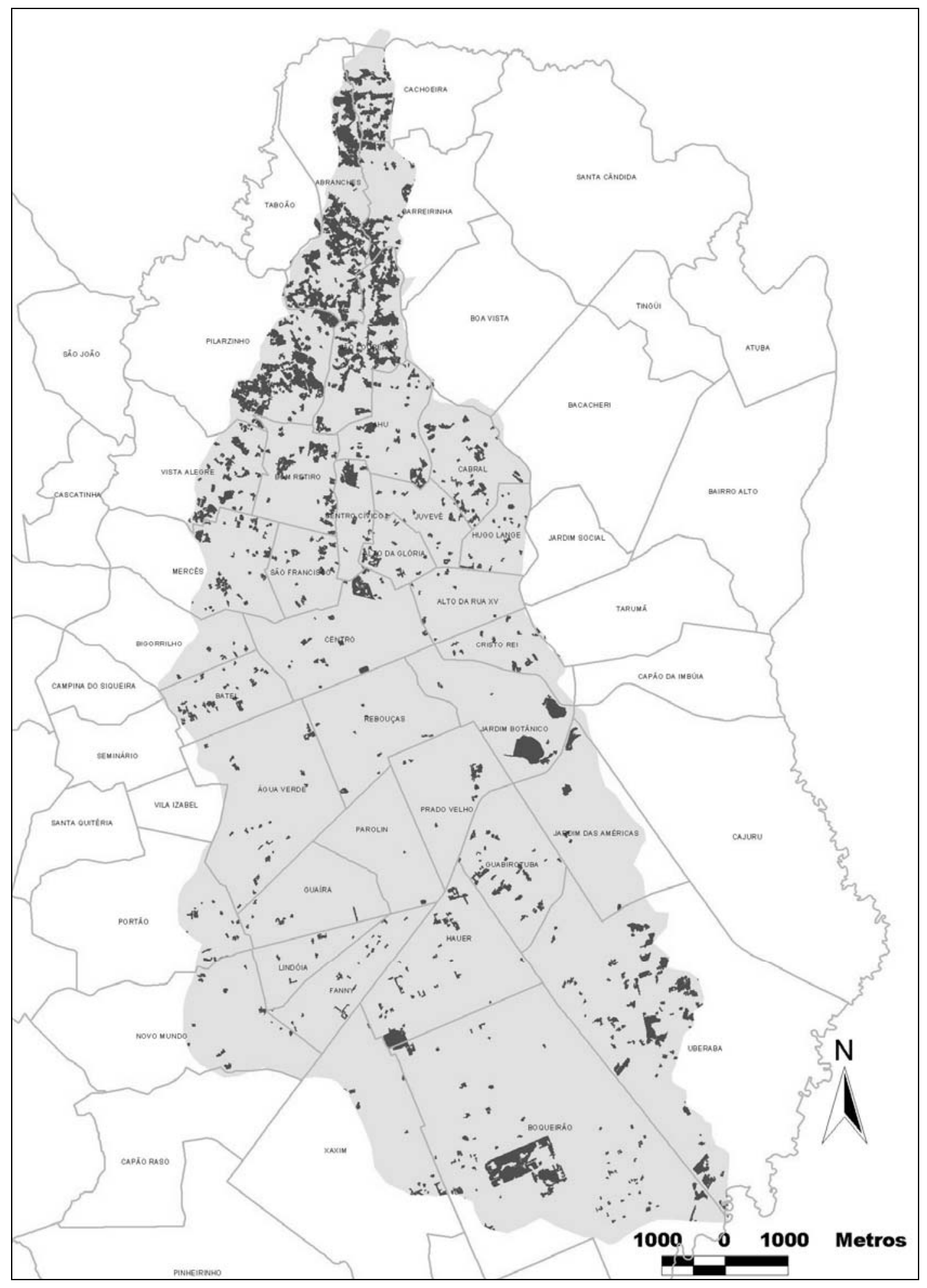

Figura 2. Bosques nativos relevantes na bacia hidrográfica do rio Belém e bairros envolvidos. Figure 2. The important native forests in river Belém watershed and their neighborhoods. 
Com os dados tabulados e trabalhados, foram geradas estatísticas referentes aos seguintes tópicos:

a) número de anos e percentual em que o entrevistado é proprietário do imóvel;

b) motivos da conservação do bosque nativo relevante no imóvel em percentual (exigência legal, valorização financeira, aspectos históricos, culturais, familiares, ecológicos e físcais);

c) conhecimento sobre os critérios e restrições de uso do imóvel com bosque nativo relevante (desconhece, conhece, conhece parcialmente);

d) número e percentual do total dos imóveis que possuem redução do IPTU;

e) percentual das faixas de redução do IPTU recebida pelos que detêm esse benefício, de acordo com os índices previstos em lei (20, 30, 40, 50, 60, 70, 80 ou 100\%);

f) número e percentual em relação aos motivos de não possuir redução de IPTU (desconhecimento, burocracia, insignificância do valor, outros). "Outros" compreende: negado pela Prefeitura e aguarda resposta da Prefeitura;

g) percepção dos benefícios que os proprietários possuem em relação aos bosques nativos relevantes no imóvel (lazer, paisagismo, conservação, valorização financeira, fiscal e sem benefício);

h) percentual de notificação e infrações sobre o uso inadequado do bosque nativo relevante nos imóveis.

\section{RESULTADOS E DISCUSSÃO}

Em relação ao número de anos em que os proprietários entrevistados detêm posse do imóvel, o resultado da pesquisa demonstrou que, do total dos proprietários dos imóveis que possuem bosques nativos relevantes, $71 \%$ residem a mais de 20 anos no local, $13 \%$ até 5 anos, $6 \%$ entre 5 e 10 anos e $10 \%$ entre 10 e 20 anos. Os resultados demonstram que 71\% dos proprietários residem no imóvel com bosques relevantes há mais de 20 anos, mas se considerarmos os que residem no imóvel há mais de 10 anos, esse total passa a ser de $81 \%$.

Em relação aos motivos que outrora resultaram na manutenção do bosque no imóvel, os resultados demonstraram que $82 \%$ dos proprietários possuem motivos históricos, culturais, familiares e ecológicos para a manutenção dos bosques, $15 \%$ por motivos de exigência legal e $3 \%$ por motivo de valorização financeira.

Na verificação do nível de conhecimento geral que os proprietários têm sobre os critérios legais em relação ao uso do solo nos imóveis que contam com bosques relevantes, com a finalidade de verificar se conhecem ou sabem que existem restrições do uso do imóvel, os resultados demonstraram que a maioria do proprietários, $63 \%$, conhece os critérios legais, $13 \%$ sabem que existem os critérios, entretanto não os conhecem com detalhes, e $21 \%$ desconhecem a existência por completo de critérios legais.

Em relação à redução e isenção de IPTU - um dos aspectos chaves da pesquisa -, buscou-se identificar a quantidade de proprietários que possuem redução do imposto, como estímulo à conservação do bosque nativo relevante existente no imóvel. Os resultados demonstraram que 59\% dos proprietários não possuem redução sobre a alíquota do IPTU e $41 \%$ possuem redução. Foi ainda verificado, em relação à redução do IPTU, o percentual de redução para os $41 \%$ que possuem algum tipo de redução, obtendo o resultado de que a maioria (55\%) dos proprietários alcançam valores de até $20 \%$ de redução. Caso se considere o patamar de $30 \%$ de redução de IPTU, o total de proprietários que obtêm essa faixa alcança $70 \%$. Em relação ao número de anos em que os proprietários usufruem da redução do IPTU, foi verificado que a maioria $(80 \%)$ possui esse benefício no máximo há 4 anos, embora e legislação tenha sido regulamentada em 1986, ou seja, há 20 anos.

Entre os 74 proprietários que não detêm redução de IPTU, identificou-se que $42 \%$ desse total não procuraram fazer a solicitação devido a desconhecimento sobre o processo de solicitação desse benefício, $23 \%$ não solicitaram pelo excesso de burocracia, $8 \%$ devido à insignificância do valor do benefício e $27 \%$ por outros motivos.

Dos benefícios atuais dos bosques no imóvel, identificou-se a percepção dos proprietários mediante a resposta com alternativas de múltipla escolha entre os critérios de lazer, conservação e proteção ambiental, paisagismo, valorização financeira e fiscal. A pesquisa procurou verificar também os que declaravam a não-existência do benefício. Os resultados demonstram que, do total dos 126 entrevistados, totalizando 226 respostas, pois as mesmas poderiam ser de múltipla escolha, 34\% 
apontaram a função de conservação e proteção ambiental dos bosques, 31\% o lazer, 27\% o paisagismo, $4 \%$ a valorização financeira, $0,9 \%$ o beneficio fiscal, sendo que $3,1 \%$ não identificaram benefícios na existência do bosque.

Os resultados sobre as infrações ambientais recebidas pelos proprietários dos imóveis com bosques nativos relevantes, de acordo com as entrevistas realizadas, demonstraram que, dos 126 entrevistados, 118 (94\%) não tiveram qualquer infração ou notificação sobre o uso inadequado do imóvel em relação ao bosque e $8(6 \%)$ tiveram algum tipo de infração as leis ambientais.

\section{CONCLUSÕES E RECOMENDAÇÕES}

O trabalho permitiu identificar a existência de uma convivência harmoniosa dos proprietários de imóveis com os bosques nativos relevantes localizados nos seus terrenos. Essa identificação pode ser evidenciada pela ausência de notificação ou infrações incidentes sobre eles. Essa conclusão foi reforçada com a declaração dos proprietários de que os bosques geram benefícios atuais, expressados pelos aspectos de proteção e conservação ambiental, lazer e paisagismo. Também ficou evidenciado que a razão da manutenção dos bosques nos imóveis foi motivada ao longo do tempo por laços familiares e culturais que os atuais proprietários possuem com os proprietários anteriores, que eram na sua maioria ancestrais.

Por outro lado, foi possível identificar que os mecanismos e critérios legais municipais para estimular a conservação desses bosques, mediante a isenção ou redução do IPTU, não funcionaram adequadamente. Tal fato fica evidenciado pelo reduzido número de proprietários que recebe os incentivos, sendo que, na maioria dos casos, a redução não ultrapassa a 30\% do valor do IPTU. Ao mesmo tempo, a maioria que não recebe redução e isenção desse imposto desconhece os critérios específicos da solicitação ou é desmotivada pela burocracia, mesmo porque os bosques já existiam nos imóveis muito tempo antes da legislação municipal de áreas verdes ser sancionada.

Os resultados também evidenciam a falta de iniciativa da administração municipal em divulgar ou informar adequadamente os proprietários sobre os possíveis benefícios a que têm direito e também facilitar a solicitação destes benefícios com o estabelecimento de procedimento claro e ágil.

Mediante os resultados da pesquisa, foi possível concluir que:

- Os valores culturais, históricos, familiares e ecológicos são as principais razões declaradas pelos proprietários que motivaram a manutenção dos remanescentes de bosques nativos relevantes, demonstrando uma convivência pacífica dos proprietários com os bosques.

- O número de anos em que os atuais proprietários residem ou têm domínio sobre o imóvel com bosque nativo ultrapassa 30 anos, o que certamente contribuiu expressivamente para a manutenção desses remanescentes, pois os atuais proprietários são descendentes de famílias que residiam no imóvel e mantiveram os bosques pelos valores dos laços e tradições familiares.

- O conhecimento que os proprietários possuem pode não ser o suficiente para motivá-los a procurar os benefícios que a legislação pode oferecer em termos de isenção ou redução do IPTU.

- Os critérios legais para uso do solo e aproveitamento dos imóveis que abrigam bosques nativos relevantes e que criaram os estímulos para a conservação dos mesmos, mediante o incentivo de redução e isenção do IPTU, são bem definidos e regulamentados a partir de 1986, em constante processo de atualização.

- Esses instrumentos legais, no que diz respeito à geração de benefícios aos proprietários e o recebimento dos incentivos, demonstraram pouca funcionalidade e aplicabilidade, verificadas pelas seguintes evidências:

- a maioria dos proprietários não usufrui da redução do IPTU, parte em virtude do desconhecimento dos mecanismos do processo de solicitação do benefício, parte devido à burocracia necessária para a sua solicitação;

- a maioria dos proprietários que detêm o benefício da redução do IPTU sobre o imóvel com bosque nativo relevante alcança o percentual máximo de $30 \%$ sobre o valor base de cálculo do imposto;

- o número de anos em que os mesmos possuem redução do IPTU, na sua maioria, não ultrapassa quatro anos, embora a regulamentação do processo de cessão deste benefício tenha iniciado em 1986;

- os proprietários não foram informados pela administração municipal da possibilidade desses benefícios e da forma de obtê-los de maneira prática e objetiva, 
pois somente conhecem os critérios legais de forma genérica e mediante divulgação nos meios de comunicação.

- A evidente deficiência na funcionalidade e aplicabilidade da legislação, especialmente em relação ao conhecimento que os proprietários possuem sobre os estímulos à conservação e aos benefícios da redução e insenção do IPTU, também pode ter origem no desinteresse dos proprietários em procurar conhecer detalhes da legislação de que declaram saber da existência, ou mesmo pela pouca atratividade que a redução do imposto pode estar oferecendo aos imóveis residenciais.

- Embora a legislação que restringe o uso dos bosques e estimule a sua conservação seja de época bem posterior à existência dos bosques e ao domínio pela maioria dos atuais proprietários sobre a área, ela poderá ser importante na conservação desses remanescentes, principalmente nas ocasiões em que ocorrer transferência do domínio desses bosques a outros segmentos, especificamente se estiverem vinculados ao setor imobiliário e que não tenham ligações históricas com as referidas áreas.

- Existe uma afinidade muito forte entre os proprietários e a existência dos bosques nos imóveis, uma vez que os benefícios associados à conservação e proteção ambiental, ao lazer e paisagismo foram os que se destacaram na percepção deles e mais os incentivaram a manter os bosques e a aproveitar os benefícios da sua existência e funções proporcionadas.

Em função dos resultados da pesquisa, no que diz respeito ao aprimoramento da política municipal de meio ambiente e sua interface com os critérios de uso do solo urbano visando à melhoria da gestão do Sistema Especial de Áreas Verdes e o cadastramento de bosques nativos relevantes, recomenda-se:

- Difundir junto aos proprietários de imóveis que possuem bosques nativos relevantes a política pública de áreas verdes de Curitiba, em especial o sistema de cadastramento e os mecanismos de incentivos à conservação desses bosques mediante a redução do IPTU, com a finalidade de beneficiar as pessoas que contribuem com a conservação dessas importantes áreas verdes urbanas.

- Estabelecer, por meio de ato normativo, a publicação da relação de bosques cadastrados no Sistema Especial de Áreas Verdes, com a localização por bairro, rua e indicação fiscal, de forma a tornar público esses dados e disponibilizar aos proprietários das áreas informações sobre os critérios legais relacionados ao uso da área e a possíveis benefícios fiscais.

- Estabelecer procedimentos claros e de fácil compreensão pelos proprietários para a solicitação e concessão dos benefícios, de forma a desburocratizar os atuais processos e facilitar a forma de solicitação.

- Regionalizar os indicadores de índice de áreas verdes por bacia hidrográfica, por regiões administrativas da Prefeitura e bairros, tanto por área física e percentagem como por habitante, de forma a oferecer maior visibilidade e credibilidade dos índices, geralmente tratados de forma genérica e centralizados no município. Essa medida poderá facilitar a compreensão desses índices pela população, bem como possibilitar a difusão de conceitos sobre as funções das florestas urbanas nas diferentes áreas dos municípios, tanto nas regiões com maior presença de áreas verdes e com menor densidade populacional como nas de maior carência, gerando, assim, a oportunidade de se criarem condições para o estabelecimento de políticas públicas de áreas verdes diferenciadas para as distintas regiões da cidade.

\section{REFERÊNCIAS}

CAVAlHeIRO, F. O planejamento de espaços livres: o caso de São Paulo. Silvicultura em São Paulo, 16(A-/), p. 1819-30, 1982. Anais do Congresso Nacional sobre Essências Nativas.

CURITIBA. Prefeitura Municipal. Legislação Municipal. Disponível em: <http://www.curitiba.pr.gov.br $>$ Acesso em: 2004

CURITIBA. Secretaria Municipal de Meio Ambiente. Coletânea de legislação ambiental de Curitiba 1998. Curitiba, 1998. 420 p.

CURITIBA. Secretaria Municipal de Meio Ambiente. Serviço de geoproecessamento - mapas de localização das áreas verdes - bacias hidrográficas. Curitiba, 2004. 
DIAS, L. C. P. IPTU - Sistema de alíquotas progressivas: função social da propriedade e a autonomia municipal. Disponível em: <http://www.direitoufal.hpg.ig.com.br $>$ e $<$ http://www.faroljuridico.com.br $>$ Acesso em: 2004.

FUNDAÇÃO DE PESQUISAS FLORESTAIS DO PARANÁ. Mapeamento das áreas verdes do município de Curitiba-PR. Curitiba, 1987. 40 p.

GREY, G. W.; DENEKE, F. J. Urban forestry. New York : J. Willey, 1978. 179 p.

GUZZO, P. Áreas verdes urbanas. Disponível em: < http -//educar.sc.usp.br/biologia/prociencias/ areasverdes.html> Acesso em: 2004.

HARDT, L. P. A. Subsídios ao planejamento de sistemas de áreas verdes baseado em princípios de ecologia urbana - aplicação a Curitiba - Pr. 171p. Dissertação (Mestrado em Ciências Florestais) Setor de Ciências Agrárias, Universidade Federal do Paraná, Curitiba, 1994.

HILDEBRAND, E. Avaliação econômica dos benefícios gerados pelos parques urbanos - estudo de caso em Curitiba, Pr. 137f. Tese (Doutorado em Ciências Florestais) - Setor de Ciências Agrárias, Universidade Federal do Paraná,, Curitiba, 2001.

INSTITUTO DE PESQUISA E PLANEJAMENTO URBANO DE CURITIBA. Censo 2000 - bairros de Curitiba. Disponível em: $<$ http -//www.ippuc.org.br/informando/index_censo2000.htm> Acesso em: 2004.

LiMA, A. M. L. P.; CAVAlHeIRO, F.; NUCCI, J. C.; SOUZA, M. A. L. B.; FIALHO, N. O.; DEL PICCHIA, P. C. D. Problemas de utilização na conceituação de termos como espaços livres, áreas verdes e correlatos. In: CONGRESSO BRASILEIRO SOBRE ARBORIZAÇÃO URBANA, 2., 1994, São Luiz. Anais... São Luiz: [s.n.], 1994. p. 539-50.

LOUREIRO, W. Experiências nacionais e internacionais em incentivos a conservação da biodiversidade. 58.f. Trabalho de Qualificação (Curso de Pós-Graduação em Engenharia Florestal da Universidade Federal do Paraná) - Universidade Federal do Paraná, Curitiba, 2002.

MIGUEZ, L. A. L. Mapeamento e monitoramento dos maciços vegetais do município de Curitiba, Pr. 36 p. Monografia (Especialização em Qualidade de Vida Urbana) - Faculdade de Administração e Economia do Paraná, Instituto de Engenharia do Paraná, 2001.

MILANO, M. S.; DISPERATI, A. A. Análise da quantidade e distribuição das áreas verdes no município de Curitiba, Pr. In: ENCONTRO NACIONAL SOBRE ARBORIZAÇÃO URBANA, 1987, Maringá. Anais... Maringá : [s.n.], 1987. v.2, p. 165-73.

NILSSON, K.; RANDRUP, T. B. Actividades forestales urbanas y periurbanas. Hørsholm Kongevej : Danish Forest and Landscape Research Institute, 1997. p 85-102. (VO1SP_T3.PM5).

NILSSON, K.; RANDRUP, T. B. Y.; TVEDT, T. Aspectos tecnológicos del enverdecimiento urbano. In: SEMINÁRIO ÁREAS VERDES URBANAS EN LATINOAMÉRICA Y EL CARIBE, 1., 1997, México. [Anais...] México : Banco Interamericano de Desarrolo, 1997. P. 39 - 81.

NUNES, M. L. Metodologia de avaliação da arborização urbana. $1^{0}$ CONGRESSO BRASILEIRO SOBRE ARBORIZAÇÃO URBANA, 1. ; ENCONTRO NACIONAL SOBRE ARBORIZAÇÃO URBANA, 4., 1992, V'tória. Anais.... Vitória : [s.n.], 1992. p 133-145.

PIRES, P. T L. A influência do Imposto Territorial Rural sobre a atividade florestal. 125f. Dissertação (Mestrado em Ciências Florestais) - Setor de Ciências Agrárias, Universidade Federal do Paraná., Curitiba, 1999.

POLAND, C. C. O verde urbano e o conservacionismo do planejamento das cidades. Boletim Informativo, Fundação Brasileira para a Conservação da Natureza, Rio de Janeiro, n. 8, p. 3-9,1973.

SANTOS, A. J. Os instrumentos fiscais da política florestal francesa. Floresta, Curitiba, v. 25, n. 1/2, p.71-7, 1995. 